\title{
MONITORAMENTO DA CONDUTIVIDADE ELÉTRICA E PH DA SOLUÇÃO DO SOLO SOB DIFERENTES DOSES DE APLICAÇÃO DE VINHAÇA
}

João Paulo Francisco ${ }^{1}$, Marcos Vinícius Folegatti ${ }^{2}$, Leonardo Batista Duarte Silva ${ }^{3}$, Jonathas Gonçalves Batista Silva $^{4}$

\section{RESUMO}

Objetivou-se, neste trabalho, avaliar a condutividade elétrica (CEs) e o pH da solução do solo cultivado com abacaxi Vitória e fertirrigado com vinhaça, de modo a suprir 0, 50, 75, 100 e $125 \%$ da recomendação de potássio para essa cultura, obtendo-se, dessa forma, os seguintes tratamentos: T1 - $0 \mathrm{~m}^{3} \mathrm{ha}^{-1}$; T2 - $231 \mathrm{~m}^{3} \mathrm{ha}^{-1}$; T3 - $347 \mathrm{~m}^{3} \mathrm{ha}^{-1}$; T4 $-462 \mathrm{~m}^{3} \mathrm{ha}^{-1}$; T5 - $578 \mathrm{~m}^{3} \mathrm{ha}^{-1}$. O experimento foi conduzido em casa de vegetação no Departamento de Engenharia de Biossistemas da ESALQ/USP. O plantio foi realizado em trincheiras abertas ao nível do solo totalmente revestidas com lona e preenchidas com solo classificado como Latossolo Vermelho Amarelo. As aplicações de vinhaça foram realizadas quinzenalmente por meio de fertirrigação utilizando sistema de irrigação por gotejamento. Foram instalados extratores nas profundidades de 0,20 m e 0,40 m e, para extração da solução, aplicou-se vácuo na tensão de $60 \mathrm{kPa}$, duas horas após o término da fertirrigação. A coleta da solução foi realizada aos 30, 120, 210 e 270 dias após início dos tratamentos. Verificou-se que os tratamentos com aplicação de vinhaça apresentaram os maiores valores de CEs nas camadas superficiais do solo. Os resultados revelaram que o $\mathrm{pH}$ diminui à medida em que se aumentou os volumes de vinhaça aplicados.

Palavras-chave: lixiviação, salinização, efluentes líquidos, reuso de água

\section{ABSTRACT \\ MONITORING OF ELECTRICAL CONDUCTIVITY OF SOIL SOLUTION UNDER DIFFERENT DOSES OF APPLICATION OF STILLAGE}

The objective of this study was to evaluate the electrical conductivity (EC) and $\mathrm{pH}$ of soil solution cultivated with Vitória pineapple and fertilized with stillage to supply 0, 50, 75, 100 and $125 \%$ of the potassium recommendation for this culture, obtaining treatments: $\mathrm{T} 1-0 \mathrm{~m}^{3} \mathrm{ha}^{-1}$; T2 $-231 \mathrm{~m}^{3} \mathrm{ha}^{-1}$; T3 - $347 \mathrm{~m}^{3} \mathrm{ha}^{-1} ; \mathrm{T} 4-462 \mathrm{~m}^{3} \mathrm{ha}^{-1} ; \mathrm{T} 5-578 \mathrm{~m}^{3} \mathrm{ha}^{-1}$. The experiment was conducted in a greenhouse at the Department of Biosystems Engineering ESALQ/USP. The planting was conducted in trenches open at ground level fully lined with canvas and filled with soil classified as Oxisol. The application of stillage were performed fortnightly through fertigation system using drip irrigation. Extractors were installed at depths of $0,20 \mathrm{~m}$ and $0,40 \mathrm{~m}$ for extraction of the solution, vacuum was applied at the tension of $60 \mathrm{kKPa}$ two hours after the fertigation. The solution was collected 30 , 120,210 e 270 days after starts of treatments. It was found that treatments with stillage application showed the highest $\mathrm{EC}$ in the soil surface layers. The $\mathrm{pH}$, otherwise, decrease with the increment on the vinasse levels.

Keywords: leaching, salinization, net effluents, water reuse

Recebido para publicação em 17/02/2015. Aprovado em 11/12/2015.

1 - Eng ${ }^{\circ}$ Agrônomo, Dep. de Eng. de Biossistemas, ESALQ/USP, PPG Eng. de Sistemas Agrícolas, Piracicaba, SP, Brasil, jpbausen@usp.br

2 - Eng ${ }^{\circ}$. Agrônomo, Departamento de Engenharia de Biossistemas, ESALQ/USP, Piracicaba, SP, Brasil, mvfolega@usp.br

3 - Eng ${ }^{\circ}$. Agrícola, Departamento de Engenharia, UFRRJ, Seropédica, RJ, Brasil, monitoreambiental@gmail.com

4 - Eng ${ }^{\circ}$. Agrícola e Ambiental, Dep. de Eng. Sanitária e Ambiental, UFJF, Juiz de Fora, MG, Brasil, jonathasbsilva@gmail.com

552 REVENG

552-561p. ENGENHARIA NA AGRICULTURA, VIÇOSA - MG, V.23 N.6, NOVEMBRO / DEZEMBRO 2015 


\section{INTRODUÇ̃̃O}

A atividade produtiva de cana-de-açúcar do Brasil é uma das mais eficientes do agronegócio mundial, sendo que a safra 2011/2012 proporcionou uma produção de 12,71 bilhões de litros de álcool (UNICA, 2012). Concomitantemente ao aumento da produção de álcool, tem-se, como consequência, a produção de vinhaça.

A vinhaça é um dos principais resíduos da fabricação do álcool, uma vez que para cada litro de álcool produzido, é gerado de 10 a 15 litros de vinhaça (WADT, 2008). Por se tratar de técnica de disposição que reduz os custos de tratamento e traz benefícios à agricultura, o aproveitamento da vinhaça por meio de fertirrigações, principalmente nas lavouras de cana-de-açúcar, tem despertado o interesse dos agricultores.

A fertirrigação com vinhaça é bastante difundida nas regiões canavieiras com resultados considerados satisfatórios em relação às alterações químicas no solo (VIANA, 2006). Porém, se realizada de forma indiscriminada, a alta concentração de nutrientes presentes na vinhaça pode resultar em aumento da lixiviação e/ou na salinidade do solo, que pode ser definida como a concentração de sais dissolvida na solução do mesmo. O aumento da concentração de sais pode resultar em menor desenvolvimento das culturas, uma vez que a planta gastará mais energia para absorver água devido à redução do potencial osmótico da água presente no solo, prejudicando seus processos metabólicos (LEONE et al., 2007). O estudo da solução do solo se faz importante por estar relacionado ao fato das plantas absorverem os nutrientes livres nesta solução e pode fornecer bons indicadores no tocante à fertilidade do solo. Porém, todo efluente, quando aplicado acima da capacidade de suporte, pode provocar contaminação do perfil do solo e das águas subterrâneas devido à lixiviação de nutrientes (ANAMI et al., 2008; PELISSARI et al. 2009).

O conhecimento de parâmetros de qualidade do solo é importante para que as plantas absorvam sem dificuldades os nutrientes presentes na solução do solo. $\mathrm{O} \mathrm{pH}$, por exemplo, é um dos indicadores das condições químicas do solo por possuir a capacidade de interferir na disposição de vários elementos essenciais ao desenvolvimento vegetal, favorecendo ou não sua absorção (BRADY, 1989).

Os íons que compõem a solução do solo podem ser adsorvidos às partículas de argila e matéria orgânica, absorvidos pelas plantas ou lixiviados das camadas superficiais do solo. Ao serem lixiviados, os nutrientes são drenados até o lençol freático e, consequentemente, transportados a grandes distâncias, contaminando os mananciais de água potável (KONRAD, 2002). Entre os atributos químicos que afetam a lixiviação estão em capacidade de retenção de íons e o pH. De acordo com Neves et al. (2009), a lixiviação dos íons varia com os atributos físicos do solo como a textura, a estrutura, a profundidade do perfil e a porosidade. A mobilidade de um íon no perfil depende de suas propriedades físicas e químicas e das propriedades inerentes à fração coloidal do solo (RIVERA et al., 2008).

O aumento da concentração de sais solúveis na solução do solo provoca a redução do potencial osmótico da água, fazendo com que as plantas gastem mais energia para absorvê-la, acarretando em efeitos negativos no desenvolvimento da produção das culturas agrícolas. Portanto, a planta pode ter o seu desenvolvimento comprometido por um estresse hídrico, mesmo com o teor de água no solo próximo à capacidade de campo.

Medidas da condutividade elétrica são frequentemente utilizadas para avaliar a concentração de sais dissolvidos no solo. Desta forma, objetivou-se neste trabalho avaliar a condutividade elétrica e o $\mathrm{pH}$ da solução de um Latossolo Vermelho Amarelo, quando submetido a diferentes doses de aplicação de vinhaça e cultivado com abacaxi.

\section{MATERIAL E MÉTODOS}

O presente estudo foi desenvolvido no Departamento de Engenharia de Biossistemas da Escola Superior de Agricultura "Luiz de Queiroz" (ESALQ/USP), localizado no município de Piracicaba, no Estado de São Paulo. Para evitar a interferência climática, no que diz respeito à precipitação, o experimento foi realizado em casa de vegetação. A área experimental foi cultivada com abacaxizeiro Vitória, plantado em trincheiras abertas ao nível do solo com dimensões de 3,20 
$\mathrm{m}$ de comprimento, $0,80 \mathrm{~m}$ de largura e $0,50 \mathrm{~m}$ de profundidade. $\mathrm{O}$ solo utilizado no preenchimento das trincheiras corresponde a um perfil classificado como Latossolo Vermelho Amarelo fase arenosa, obtida na profundidade de $0,30 \mathrm{~m}$ da camada agricultável, proveniente do campus da ESALQ. As unidades experimentais foram preenchidas com o solo de modo a obter características físicas homogêneas, tais como volume de solo semelhante por unidade, forma e disposição espacial. Para obtenção de um sistema fechado, as trincheiras foram revestidas com lona plástica. No Quadro1 apresenta-se a caracterização química e física do solo utilizado no experimento.

A área experimental foi constituída de 20 unidades experimentais, sendo efetuado o plantio de 16 plantas em cada delas, e o experimento foi composto de cinco tratamentos e quatro repetições. Os tratamentos foram caracterizados pela aplicação de cinco níveis de vinhaça, sendo: T1- $0 \mathrm{~m}^{3} \mathrm{ha}^{-1}$ (adubação química); T2 - $231 \mathrm{~m}^{3} \mathrm{ha}^{-1}$; T3 $-347 \mathrm{~m}^{3}$ ha ${ }^{-1} ; \mathrm{T} 4-462 \mathrm{~m}^{3} \mathrm{ha}^{-1} ; \mathrm{T} 5-578 \mathrm{~m}^{3} \mathrm{ha}^{-1}$. As aplicações ocorreram em intervalos de 15 dias utilizando-se um sistema de irrigação localizada com gotejadores de vazão nominal de $4 \mathrm{~L} \mathrm{~h}^{-1}$ espaçados em 0,40 m. Os volumes de vinhaça aplicados foram calculados seguindo-se recomendações da norma CETESB P4.231, de modo que o tratamento T4 supriu $100 \%$ da demanda por potássio do abacaxizeiro por meio da vinhaça e os outros receberam doses correspondentes a $0 \%(\mathrm{~T} 1), 50 \%(\mathrm{~T} 2), 75 \%$ (T3) e $125 \%$ (T5). O tratamento T1 teve $100 \%$ do suprimento de potássio realizado por meio da aplicação de cloreto de potássio.

No Quadro 2 apresentam-se as características da vinhaça utilizadas no experimento. Tornase importante ressaltar que os valores são uma média dos volumes coletados e aplicados durante a condução do experimento. As análises foram realizadas no Laboratório de Solos e Qualidade de Água do Departamento de Engenharia de Biossistemas da ESALQ/USP.

As amostras de solução de solo foram coletadas aos 30, 120, 210 e 270 dias após início dos tratamentos com aplicação de vinhaça (DAIT). A coleta foi realizada por meio de extratores de solução providos de cápsulas porosas previamente instalados nas profundidades de 0,20 e $0,40 \mathrm{~m}$, a

Quadro 1. Caracterização química do Latossolo Vermelho Amarelo.

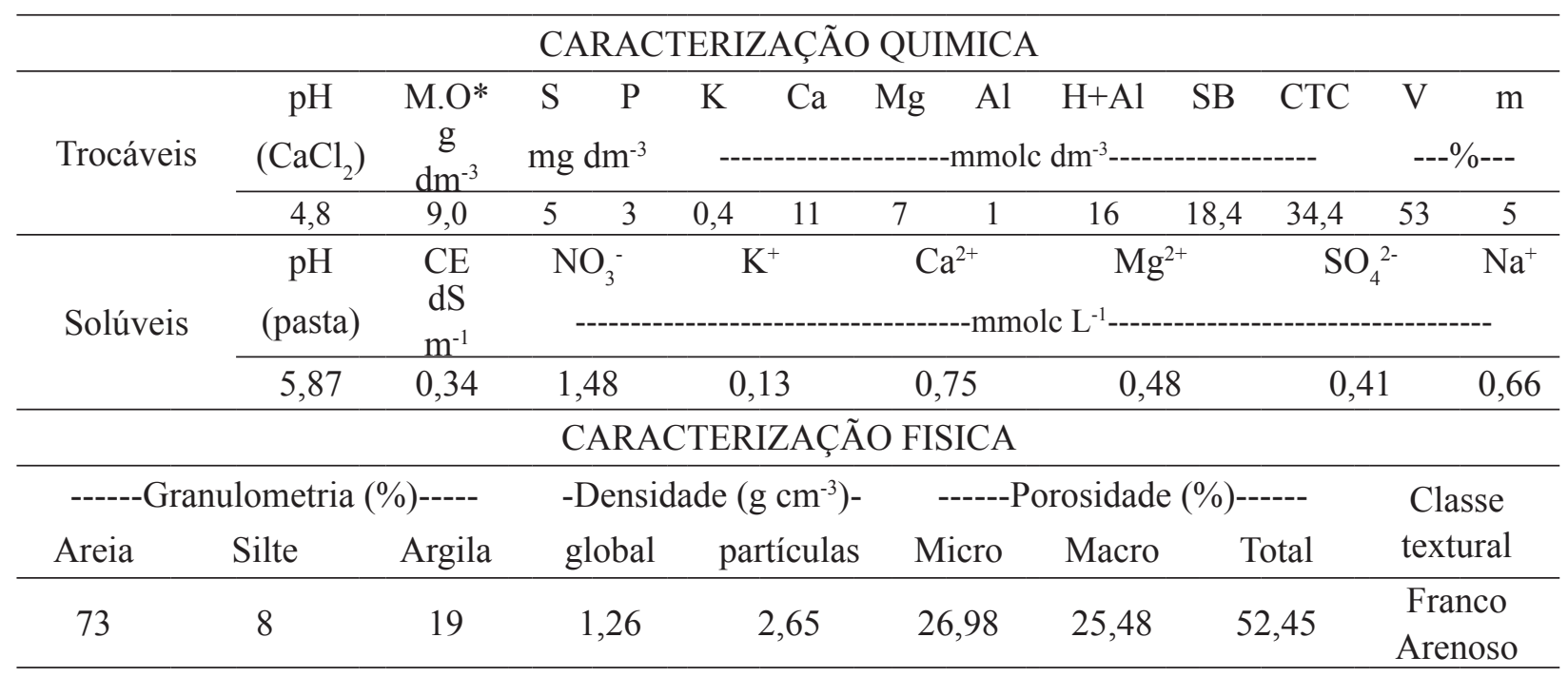

Quadro 2. Caracterização da vinhaça utilizada nos tratamentos.

\begin{tabular}{cccccccc}
\hline $\begin{array}{c}\text { DQO } \\
\left(\mathrm{mg} \mathrm{L}^{-1}\right)\end{array}$ & $\begin{array}{c}\mathrm{DBO} \\
\left(\mathrm{mg} \mathrm{L}^{-1}\right)\end{array}$ & $\begin{array}{c}\mathrm{ST} \\
\left(\mathrm{mg} \mathrm{L}^{-1}\right)\end{array}$ & $\begin{array}{c}\text { Condutividade } \\
\left(\mathrm{mS} \mathrm{cm}^{-1}\right)\end{array}$ & $\mathrm{pH}$ & $\begin{array}{c}\text { Nitrato } \\
\left(\mathrm{mg} \mathrm{L}^{-1}\right)\end{array}$ & $\begin{array}{c}\text { Potássio } \\
\left(\mathrm{mg} \mathrm{L}^{-1}\right)\end{array}$ & $\begin{array}{c}\text { Sódio } \\
\left(\mathrm{mg} \mathrm{L}^{-1}\right)\end{array}$ \\
\hline $36.845,7$ & $6.683,7$ & $33.434,5$ & $7.110,00$ & 4,08 & 124,0 & $3.568,5$ & 49,0 \\
\hline
\end{tabular}


uma distância de $0,15 \mathrm{~m}$ da planta e dos emissores. A aplicação do vácuo, na tensão de $60 \mathrm{kPa}$, para retirada das amostras foi realizada com uma bomba de vácuo manual. $\mathrm{O}$ vácuo foi aplicado 2 horas após término da aplicação de vinhaça e a coleta da solução foi realizada 24 horas após a aplicação do vácuo. Em seguida, as amostras de solução foram acondicionadas em recipientes hermeticamente fechados e transportadas para o Laboratório de Solos e Qualidade de Água do Departamento de Engenharia de Biossistemas da ESALQ/USP, onde foram determinados os valores de condutividade elétrica (CEs) e pH por meio de condutivímetro e potenciômetro de bancada.

Inicialmente, os dados experimentais foram submetidos aos testes de Shapiro-Wilk $(\mathrm{P}>$ $0,01)$ e de Levene $(\mathrm{P}>0,01)$, para verificação da normalidade e homocedasticidade residuais, e posteriormente, realizou-se a análise de variância.

Os dados foram submetidos à análise de variância, com desdobramento dos efeitos quantitativos em polinômios ortogonais, segundo sua significância pelo Teste F. A escolha do modelo de regressão foi feita com base no modelo de maior grau significativo pelo Teste $\mathrm{F}$ que apresentava comportamento biológico. Tanto para a análise de variância quanto à estimativa dos parâmetros dos modelos da regressão, foi utilizado o programa estatístico Statistical Analysis System, versão 9.3.

\section{RESULTADOS E DISCUSSÃO}

Os dados coletados apresentaram distribuição normal e homocedasticidade residual conforme resultados obtidos pelo teste de Shapiro-Wilk e Levene, portanto não foi necessária a transformação dos dados obtidos.

No Quadro 3 apresenta-se o resumo da análise de variância da regressão para a condutividade elétrica da solução do solo (CEs) coletada aos 30 , 120, 210 e 270 DAIT. De acordo com a análise de variância da regressão para massa dos frutos houve efeito significativo das doses de vinhaça, em nível de 0,01 de significância

As equações ajustadas nas duas profundidades e em cada tempo de coleta são apresentadas na Figura 1.

$\mathrm{Na}$ avaliação realizada aos 30 DAIT (Figura 1A), verificou-se que os tratamentos que se caracterizaram pela aplicação de vinhaça apresentaram os maiores valores de CEs nas duas profundidades avaliadas. As equações ajustadas seguiram modelo quadrático e os maiores valores de CEs estimados para as profundidades de 0,20 e $0,40 \mathrm{~m}$ foram de $2.358,8$ (T4) e $2.488,0 \mu \mathrm{S}$ $\mathrm{cm}^{-1}$ (T5), respectivamente. Os valores mínimos foram de 1.409,2 (T1) e 892,0 $\mu \mathrm{S} \mathrm{cm} \mathrm{cm}^{-1}$ (T1), respectivamente para as profundidades de $0,20 \mathrm{e}$ $0,40 \mathrm{~m}$.

Conforme avaliação realizada aos 120 DAIT (Figura 1B), houve interação significativa das doses

Quadro 3. Resumo da análise de variância da regressão referente à condutividade elétrica da solução do solo em duas profundidades aos 30, 120, 210 e 270 DAIT

\begin{tabular}{|c|c|c|c|c|c|c|c|c|c|}
\hline \multirow{3}{*}{$\begin{array}{l}\text { Fonte de } \\
\text { Variação }\end{array}$} & \multirow{3}{*}{ GL } & \multicolumn{8}{|c|}{ TESTE F } \\
\hline & & \multicolumn{4}{|c|}{$\mathrm{CE}(20 \mathrm{~cm})$} & \multicolumn{4}{|c|}{$\mathrm{CE}(40 \mathrm{~cm})$} \\
\hline & & 30DAIT & 120DAIT & 210DAIT & 270DAIT & 30DAIT & 120DAIT & 210DAIT & 270DAIT \\
\hline Linear & - & $63,79 * *$ & $114,12^{* *}$ & $59,45^{* *}$ & $29,73^{* *}$ & $135,65^{* *}$ & $54,57^{* *}$ & $22,91 * *$ & $4,80^{\mathrm{ns}}$ \\
\hline Quadrática & - & $11,19 * *$ & $60,10^{* *}$ & $2,95^{\mathrm{ns}}$ & $1,40^{\text {ns }}$ & $37,32 * *$ & $13,29 * *$ & $0,03^{\text {ns }}$ & $0,17^{\mathrm{ns}}$ \\
\hline Cúbica & - & $2,05^{\mathrm{ns}}$ & $16,57^{* *}$ & $0,04^{\text {ns }}$ & $0,69^{\text {ns }}$ & $1,55^{\text {ns }}$ & $0,15^{\mathrm{ns}}$ & $22,62 * *$ & $94,20 * *$ \\
\hline Tratamentos & 4 & $19,64 * *$ & $48,63 * *$ & $17,30 * *$ & $7,98 * *$ & $45,80^{* *}$ & $40,02 * *$ & $12,84 * *$ & $25,50 * *$ \\
\hline CV (\%) & - & 7,73 & 8,13 & 15,82 & 20,52 & 8,74 & 9,39 & 23,35 & 18,12 \\
\hline $\begin{array}{l}\text { M é d i a } \\
\left(\mu \mathrm{S} \mathrm{m}^{-1}\right)\end{array}$ & - & $2.085,20$ & $1.850,173$ & $1.486,50$ & 462,49 & $2.040,83$ & $1.735,03$ & $1.462,373$ & 446,35 \\
\hline
\end{tabular}



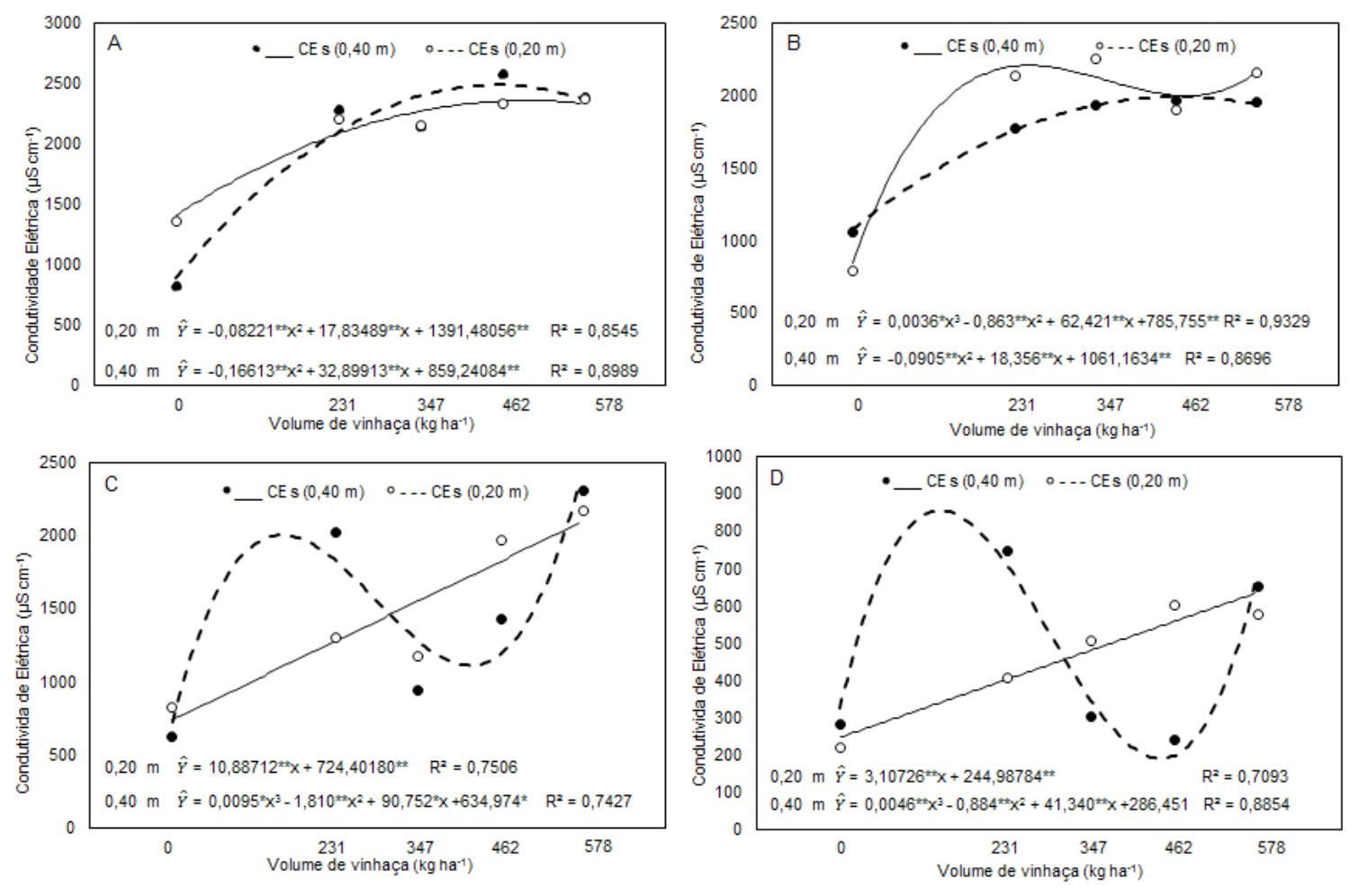

* termos independentes da equação significativo a 0,05 de significância pelo Teste $F$

*z termos independentes da equação significativos a 0,01 de significância pelo Teste $F$

Figura 1. Diagramas de dispersão e equações de ajustes da CEs para as coletas realizadas aos 30 (A), 120 (B), 210 (C) e 270 (D) DAIT nas profundidades de 0,20 e $0,40 \mathrm{~m}$ em função dos volumes de vinhaça aplicado.

de vinhaça aplicada sobre a CEs na solução do solo. As equações ajustadas seguiram modelo quadrático para a profundidade de $0,20 \mathrm{~m}$ e cúbica para 0,40 $\mathrm{m}$, sendo os maiores valores de CEs estimados para as profundidades de 0,20 e $0,40 \mathrm{~m}$ de $2.207,2$ (T4) e $1.991,7 \mu \mathrm{S} \mathrm{cm}^{-1}$ (T5), respectivamente. Os valores mínimos foram de 847,3 (T1) e 1.079,4 $\mu \mathrm{S}$ $\mathrm{cm}^{-1}(\mathrm{~T} 1)$, respectivamente para as profundidades de 0,20 e $0,40 \mathrm{~m}$.

Nas avaliações realizadas aos 210 e 270 DAIT (Figuras 1C e 1D, respectivamente), foi verificado um aumento linear da CEs na profundidade de 0,20 $\mathrm{m}$, com valores máximos e mínimos estimados de $2.085,3$ (T5) e $735,3 \mu \mathrm{S} \mathrm{cm}^{-1}$ (T1) e 633,4 (T5) e $248,1 \mu \mathrm{S} \mathrm{cm} \mathrm{cm}^{-1}$ (T1), respectivamente para as avaliações aos 210 e 270 DAIT. Nota-se que a CEs da solução do solo diminuiu na avaliação realizada aos 270 DAIT, uma vez que neste período já havia cessado as fertirrigações com vinhaça, portanto neste período só houve a extração de nutrientes por parte da planta de abacaxi. Vale ressaltar que a avaliação aos 210 DAIT foi realizada após a última fertirrigação com vinhaça.

As equações de ajustes para a profundidade de $0,40 \mathrm{~m}$ seguiram modelo cúbico nas coletas realizadas aos 210 e 270 DAIT. Nesta profundidade, os tratamentos com aplicações de 347 e $578 \mathrm{~kg} \mathrm{ha}^{-1}$ de vinhaça apresentaram os maiores valores de CEs em profundidade. $\mathrm{O}$ alto volume de vinhaça fornecido ao T5 $\left(578 \mathrm{~kg} \mathrm{ha}^{-1}\right)$ promoveu aumento na concentração de sais no solo, resultando nos elevados valores de $\mathrm{CE}$ encontrados neste tratamento nas avaliações realizadas aos 210 e 270 DAIT.

Os tratamentos com maiores volumes de vinhaça aplicados apresentaram os maiores valores de CEs. Marinho, Fernandes \& Gheyi (1998), verificaram que a condutividade elétrica do solo deve ser inferior a $4.000 \mu \mathrm{S} \mathrm{cm}^{-1}$ para garantir um pleno desenvolvimento vegetativo à cultura do 
abacaxi. Portanto, não foi verificado esse valor em nenhum dos tratamentos avaliados.

$\mathrm{O}$ acréscimo da CE com o aumento das doses de vinhaça aplicada foi sempre superior ao tratamento com adubação química, principalmente na profundidade de $0,20 \mathrm{~m}$. Isto ocorreu porque o aumento da concentração eletrolítica da solução do solo é proporcional ao incremento na concentração de íons na solução. Maiores valores de CEs em superfície também foram verificados por Porto Filho et al. (2011) e Oliveira (2012), de acordo com os autores, estes resultados podem estar associados à maior evapotranspiração na camada superior, aliada ao uso de fertilizantes aplicados na superfície via água de irrigação. Os mesmos autores afirmam que quando não há impedimento físico, os sais lixiviam para além das camadas monitoradas; no entanto, esta afirmação não se enquadra para a presente pesquisa, pois o volume de solo disponível para as plantas se encontrava limitado por uma barreira física (lona plástica), impedindo a interferência da solução entre as parcelas e sua lixiviação para zonas além do sistema radicular.

A característica arenosa do solo utilizado no experimento, aliada à baixa capacidade de troca de cátions (CTC), permitiu que a mobilidade dos íons no Latossolo vermelho amarelo fosse muito grande, com distribuição de sais bastante homogênea ao longo do seu perfil. O potencial de saturação de sais dos solos arenosos é baixo, portanto os valores de condutividade elétrica elevados encontrados neste estudo podem ser atribuídos à menor retenção de sais por parte do Latossolo vermelho amarelo, resultando em uma lenta interação entre o solo e a vinhaça aplicada, provocada pela maior permeabilidade e baixa CTC.

$\mathrm{O}$ potencial hidrogeniônico $(\mathrm{pH})$ foi afetado pelas doses de vinhaça aplicada em todas as coletas realizadas, a 0,01 de significância, conforme apresentado no Quadro 4.

$\mathrm{Na}$ Figura 2 apresenta-se o efeito das fertirrigações com vinhaça sobre o $\mathrm{pH}$ aos 30 , 120, 210 e 270 DAIT, ajustando-se equações para cada tempo e profundidade em função das doses de vinhaça. Observa-se que houve uma diminuição do $\mathrm{pH}$ ao longo do tempo de coleta nos tratamentos que receberam aplicações de vinhaça, este resultado pode estar associado à liberação de $\mathrm{CO}_{2}$ e ácidos orgânicos durante a degradação da matéria orgânica pelos microrganismos (NOVAIS et al., 2007).

$\mathrm{Na}$ avaliação realizada aos 30 DAIT (Figura 2A), verificou-se que o $\mathrm{pH}$ na profundidade de 0,40 $\mathrm{m}$ teve um ajuste quadrático, sendo observados maiores valores de $\mathrm{pH}$ nos tratamentos que tiveram fertirrigação com vinhaça e adubação química. Neste sentido, a combinação de doses de vinhaça com adubação química promoveu, inicialmente, diminuição no $\mathrm{pH}$ da solução do solo.

Conforme avaliação aos 120, 210 e 270 DAIT (Figuras 2B, C e D, respectivamente), a solução do solo teve uma diminuição no $\mathrm{pH}$ quando comparado à primeira avaliação, tanto na profundidade de 0,20 m quanto na profundidade de $0,40 \mathrm{~m}$. Vale ressaltar

Quadro 4. Resumo da análise de variância da regressão referente à condutividade elétrica da solução do solo em duas profundidades aos 30, 120, 210 e 270 DAIT.

\begin{tabular}{|c|c|c|c|c|c|c|c|c|c|}
\hline \multirow{3}{*}{$\begin{array}{l}\text { Fonte de } \\
\text { Variação }\end{array}$} & \multirow{3}{*}{ GL } & \multicolumn{8}{|c|}{ TESTE F } \\
\hline & & \multicolumn{4}{|c|}{$\mathrm{pH}(20 \mathrm{~cm})$} & \multicolumn{4}{|c|}{$\mathrm{pH}(40 \mathrm{~cm})$} \\
\hline & & 30DAIT & 120DAIT & 210DAIT & 270DAIT & 30DAIT & 120DAIT & 210DAIT & 270DAIT \\
\hline Linear & - & $816,24 * *$ & $1,62 \mathrm{~ns}$ & $0,09^{\text {ns }}$ & $0,53^{\mathrm{ns}}$ & $10,59 * *$ & $0,07^{\mathrm{ns}}$ & $6,27^{*}$ & $12,61 *$ \\
\hline Quadrática & - & $16,74^{* *}$ & $185,67 * *$ & $100,23 * *$ & $55,59 * *$ & $28,43^{* *}$ & $112,23 * *$ & $32,62 * *$ & $5,63^{*}$ \\
\hline Cúbica & $\begin{array}{l}- \\
-\end{array}$ & $0,01^{\mathrm{ns}}$ & $12,30 * *$ & $30,52 * *$ & $60,66^{* *}$ & $3,53^{\text {ns }}$ & $26,84 * *$ & $6,80^{*}$ & $0,52^{\mathrm{ns}}$ \\
\hline Tratamentos & 4 & $8,27 * *$ & $67,11^{* *}$ & $45,25^{* *}$ & $38,87^{* *}$ & $11,03 * *$ & $36,18^{* *}$ & $15,15^{* *}$ & $12,27 * *$ \\
\hline CV (\%) & - & 1,36 & 1,62 & 2,45 & 3,30 & 1,46 & 2,48 & 3,98 & 4,64 \\
\hline Média & $\begin{array}{l}- \\
-\end{array}$ & 6,87 & 5,96 & 6,02 & 5,84 & 7,09 & 5,79 & 5,54 & 5,59 \\
\hline
\end{tabular}



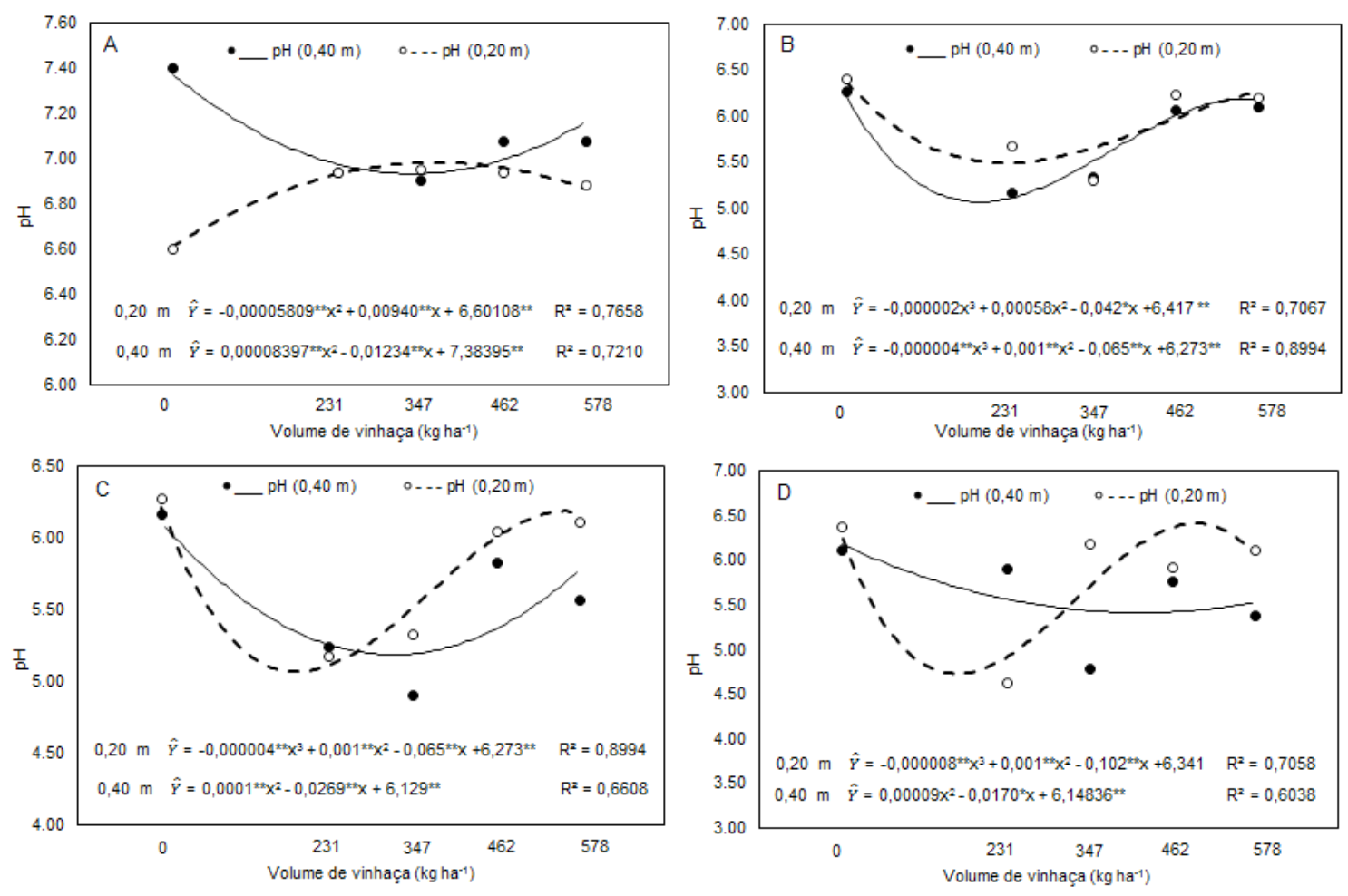

* termos independentes da equação significativo a 0,05 de significância pelo Teste $F$

** termos independentes da equação significativos a 0,01 de significância pelo Teste $F$

Figura 2. Diagramas de dispersão e equações de ajustes do $\mathrm{pH}$ para a coleta da solução do solo realizadas aos 30,120, 210 e 270 DAIT nas profundidades de 0,20 e $0,40 \mathrm{~m}$ em função dos volumes de vinhaça aplicado.

que mesmo na avaliação aos 270 DAIT, quando as aplicações de vinhaça já haviam cessado, o pH permaneceu praticamente inalterado na solução do solo.

Segundo Silva e Mendonça (2007), a degradação da matéria orgânica pelos microrganismos nas camadas mais superficiais do solo pode proporcionar diminuição no valor do $\mathrm{pH}$ devido à produção de $\mathrm{CO}_{2}$ e de ácidos orgânicos. No processo de decomposição da matéria orgânica há formação tanto de ácidos orgânicos como de inorgânicos. O ácido mais simples e encontrado em maior abundância é o carbônico, que resulta da combinação do óxido carbônico com a água. Por ser um ácido fraco não pode ser responsabilizado pelos baixos valores de $\mathrm{pH}$ do solo. Os ácidos inorgânicos, como os ácidos sulfúrico e nítrico, e alguns ácidos orgânicos fortes, são potentes supridores de íons de hidrogênio do solo. A acidez do solo surge com o contato dos ácidos do solo com a solução aquosa, dissociando em ânion e hidrogênio.

Pode-se verificar que o comportamento do $\mathrm{pH}$ foi o mesmo em todas as análises realizadas, praticamente não se alterando, mesmo com as aplicações de vinhaça no solo. Estes resultados divergem dos encontrados por Medeiros et al. (2005), que avaliando variações do $\mathrm{pH}$ do solo quando foi aplicada água residuária de origem doméstica, constataram incremento significativo em relação às áreas que receberam calagem e adubação química. Lo Monaco et al. (2009) verificaram o aumento do $\mathrm{pH}$ no solo após a aplicação da água residuária do beneficiamento do fruto do cafeeiro e atribuíram esse resultado ao aumento na concentração de potássio trocável no solo. No entanto, Queiroz et al. (2004), ao aplicar águas residuárias da suinocultura por escoamento superficial em rampas cultivadas com gramíneas forrageiras, observaram decréscimo no $\mathrm{pH}$ do solo.

Hati et al. (2007) não verificaram alterações nos valores do $\mathrm{pH}$ com aplicações sucessivas de

\section{REVENG


efluentes de destilaria, os autores atribuem este resultado ao alto poder tampão do solo em que os trabalhos foram realizados. Rajesh et al. (2009) verificaram um aumento no $\mathrm{pH}$ do solo $(7,90$ para 8,07) ao aplicarem efluente de refinaria de petróleo durante vários intervalos de tempos. Segundo os autores, esse resultado se deu pelo efluente apresentar característica alcalina e altas concentrações de sais solúveis. Ao avaliarem o efeito das aplicações de água residuária de suinocultura no solo, Cabral et al. (2011) não verificaram variações significativas nos valores de $\mathrm{pH}$ com as doses do efluente aplicado (Maggi et al., 2013).

Segundo Lo Monaco et al. (2009), o efeito da adição de matéria orgânica sobre o $\mathrm{pH}$ do solo tem sido controverso e bastante discutido na literatura. Porém, sabe-se que quando se adiciona $\mathrm{N}$ orgânico no solo, como ocorre com as aplicações de vinhaça, o mesmo sofre processo de mineralização e, para que as plantas possam absorver este nitrogênio, um dos processos que ocorrem é o de nitrificação. A reação de nitrificação envolve a transferência de oito elétrons, desta forma essa reação representa importante contribuição para a acidificação de solos agrícolas (CANTARELLA, 2007).

\section{CONCLUSÕES}

- A condutividade elétrica do solo aumentou e o $\mathrm{pH}$ diminuiu à medida em que se aumentou os volumes de vinhaça aplicados;

- Maiores valores de CEs foram obtidos nas camadas mais superficiais do solo;

- Em nenhum dos tratamentos os valores de CEs e $\mathrm{pH}$ apresentaram valores críticos para o desenvolvimento do abacaxizeiro.

\section{AGRADECIMENTOS}

Este trabalho é parte da dissertação do primeiro autor, com projeto (2012/04806-7) financiado pela Fundação de Amparo à Pesquisa do Estado de São Paulo - FAPESP.

\section{REFERÊNCIAS BIBLIOGRÁFICAS}

ANAMI, M.H.; SAMPAIO, S.C.; SUSZEK,
M.; FRIGO, E.P. Lixiviação de nitrato e fosfato proveniente de água residuária da suinocultura tratada em sistema de lagoas. Revista Irriga, Botucatu, v.12, n.2, p.192-201, 2007.

BRADY, N.C. Natureza e propriedades dos solos. Rio de Janeiro: Freitas Bastos, 1989. 878p.

CABRAL, J.R.; FREITAS, P.S.L.; REZENDE, R.; MUNIZ, A.S.; BERTONHA, A. Impacto da água residuária de suinocultura no solo e na produção de capim-elefante. Revista Brasileira de Engenharia Agrícola e Ambiental, v. 15, n.8, p.823-831, 2011.

CANTARELLA, H. Nitrogênio. In: NOVAIS, R.F.; ALVAREZ, V.H.; BARROS, N.F.; FONTES, R.L.F.; CANTARUTTI, R.B.; NEVES, J.C. L.(Ed.). Fertilidade do solo. Viçosa: Sociedade Brasileira de Ciência do Solo, 2007. cap.7, p.375470.

COSTA, J.P. Fisiologia pós-colheita e qualidade de abacaxi 'Golden' produzidos na Paraíba. 2009. 103p. Dissertação (Mestrado em Agronomia) - Universidade Federal da Paraíba, Areia, 2009.

HATI, K.M.; K.M.; BISWAS, A.K.; BANDYOPADHYAY, K.K.; MISRA, A.K. Soil properties and crop yields on a vertisol in India with application of distillery effluent. Soil and Tillage Research, v.92, n.1-2, p. 60-68, 2007.

KONRAD, M. Efeito de sistemas de irrigação localizada sobre a produção e qualidade da acerola (Malpighia spp) na região da Nova Alta Paulista. 2002. 134p. Dissertação (Mestrado em Sistema de Produção) Faculdade de Engenharia, Universidade Estadual Paulista, Ilha Solteira, 2002.

LEONE, A.P.; MENENTI, M.; BUONDONNO, A.; LETIZIA, A.; MAFFEI, C.; SORRENTINO, G. A field experiment on spectrometry of crop response to soil salinity. Agricultural Water Management, v.89, n.1-2, p.39-48, 2007. LO MONACO, P.A.; MATOS, A.T.; MARTINEZ, H.E.P.; FERREIRA, P.A.; MOTA, M.M. Características químicas do solo após a fertirrigação 
do cafeeiro com águas residuárias da lavagem e descascamento de seus frutos. Irriga, Botucatu, v.14, n.3, p.348-364, 2009.

MAGGI, C.F.; FREITAS, P.S.L.; SAMPAIO, S.C; DIETER, J. Impacts of the application of swine wastewater in percolate and in soil cultivated with soybean. Engenharia Agrícola, v.33, n.2, p.279290, 2013.

MARINHO, F.J.L.; FERNENDES, P.D.; GHEYI, H.R. Desenvolvimento inicial do abacaxizeiro, cv. Smooth Cayenne, sob diferentes condições de salinidade da água. Revista Brasileira de Engenharia Agrícola e Ambiental, Campina Grande, v.2, n.1, p.1-5, 1998.

MARINHO, F.J.L.; FERNANDES, P D.; GHEYI, H.R. Desenvolvimento inicial do abacaxizeiro, cv. Smooth Cayenne, sob diferentes condições de salinidade da água. Revista Brasileira de Engenharia Agrícola e Ambiental, Campina Grande, v.2, n.1, p.1-5, 1998.

MEDEIROS, S.S.; SOARES. A.A.; FERREIRA, P.A.; NEVES, J.C.L.; MATOS, A.T.; SOUZA, J.A.A. Utilização de água residuária de origem doméstica na agricultura: Estudo das alterações químicas do solo. Revista Brasileira de Engenharia Agrícola e Ambiental, Campina Grande, v.9, n.4, p.603-612, 2005.

NEVES, L.S.; ERNANI, P.R.; SIMONETE, M.A. Mobilidade de potássio em solos decorrente da adição de doses de cloreto de potássio. Revista Brasileira de Ciência do Solo, Viçosa, v.33, n.1, p.25-32, 2009.

NOVAIS, R. F.; ALVAREZ, V.H.; BARROS, N.F.; CANTARUTTI, R.B.; NEVES, J.C.L. Fertilidade do solo. Viçosa: Viçosa Sociedade Brasileira de Ciência do Solo, 2007. 1017p.

OLIVEIRA, F.A. Cultivo de pimentão em ambiente protegido utilizando diferentes manejos de fertirrigação. 2012. 222p. Tese (Doutorado em Irrigação e Drenagem) - Escola Superior de Agricultura "Luiz de Queiroz",
Universidade de São Paulo, Piracicaba, 2012.

PELISSARI, R.; SAMPAIO, S.C.; GOMES, S.D.; CREPALLI, M.S. Lodo têxtil e água residuária da suinocultura na produção de mudas de eucalyptus grandis (W, Hill ex Maiden). Engenharia Agrícola, Jaboticabal, v.29, n.2, p.288-300. 2009.

PORTO FILHO, F.Q.; MEDEIROS, JF.; GHEYI, H.R.; DIAS, N.S.; SOUSA, P.S.; DANTAS, D.C. Evolução da salinidade e pH de solo sob cultivo de melão irrigado com água salina. Revista Brasileira de Engenharia Agrícola e Ambiental, Campina Grande, v.15, n.11, p.1130-1137, 2011.

QUEIROZ, F.M.; MATOS, A.T.; PEREIRA, O.G.; OLIVEIRA, R.A.; LEMOS, A.F. Características químicas do solo e absorção de nutrientes por gramíneas em rampas de tratamento de águas residuárias da suinocultura. Revista Engenharia na Agricultura, Viçosa, MG, v.12, n.2, p.77-90, 2004.

RAJESH, D.; SUNIL, C.; LALITA, R.; SUSHILA, $\mathrm{S}$. Impact assessment of soils treated with refinery effluent. European Journal of Soil Biology, v.45, n.5-6, p.459-465, 2009.

RIVERA, N.C.R.; HONORIO, J.M. DUARTE, S.N.; BOTREL, T.A. Model applied to water and potassium dynamics under drip irrigation: sensitivity analysis. Engenharia Agrícola, v.28, n.3, p.448, 2008.

SANTOS, A.B.; FAGERIA, N.K.; ZIMMERMANN, F.J.P. Atributos químicos do solo afetado pelo manejo da água e do fertilizante potássico na cultura de arroz irrigado. Revista Brasileira de Engenharia Agrícola e Ambiental, Campina Grande, v.6, n.1, p.12-16, 2002.

SILVA, I.R.; MENDONÇA, E.S. Matéria orgânica do solo. NOVAIS, R.F.; ALVAREZ, V.H.; BARROS, N.F.; FONTES, R.L.F.; CANTARUTTI, R.B.; NEVES, J.C.L.(Ed.). Fertilidade do solo. Viçosa: Sociedade Brasileira de Ciência do Solo, 2007. cap.6, p.275-374. 
UNICA - UNIAO DA INDUSTRIA DE CANADE-AÇUCAR. Notícias. Disponível em: http:// www.unica.com.br/noticias. Acesso em: 12 fev. 2012.

WADT, L.C. Cultivo de Pleurotus spp. Em vinhaça visando à produção de biomassa e exopolissacarídeos. 2008. 72p. Dissertação (Mestrado em Biologia na Agricultura e no Ambiente) - Centro de Energia Nuclear na
Agricultura, Universidade de São Paulo, Piracicaba, 2008.

VIANA, A.B. Tratamento anaeróbio da vinhaça em reator UASB operado em temperatura na faixa termofílica $\left(55^{\circ} \mathrm{C}\right)$ e submetido ao aumento progressivo de carga orgânica. 2006. 102p. Dissertação (Mestrado em Hidráulica e Saneamento) - Escola de Engenharia de São Carlos, Universidade de São Paulo, São Carlos, 2006. 